\title{
The effect of ivermectin ${ }^{\circledR}$ on fertility, fecundity and mortality of Anopheles arabiensis fed on treated men in Ethiopia
}

\author{
Wondemeneh Mekuriaw ${ }^{1,6^{*}}$ (1), Meshesha Balkew² ${ }^{2}$ Louisa A. Messenger ${ }^{3}$, Delenasaw Yewhalaw ${ }^{4,5}$, \\ Adugna Woyessa ${ }^{1}$ and Fekadu Massebo ${ }^{6}$
}

\begin{abstract}
Background: Insecticide resistance is a growing threat to malaria vector control. Ivermectin, either administered to humans or animals, may represent an alternate strategy to reduce resistant mosquito populations. The aim of this study was to assess the residual or delayed effect of administering a single oral dose of ivermectin to humans on the survival, fecundity and fertility of Anopheles arabiensis in Ethiopia.

Methods: Six male volunteers aged 25-40 years (weight range 64-72 kg) were recruited; four of them received a recommended single oral dose of $12 \mathrm{mg}$ ivermectin and the other two individuals were untreated controls. A fully susceptible insectary colony of An. arabiensis was fed on treated and control participants at 1, 4, 7, 10 and 13 days post ivermectin-administration. Daily mosquito mortality was recorded for 5 days. An. arabiensis fecundity and fertility were measured from day 7 post treatment, by dissection to examine the number of eggs per mosquito, and by observing larval hatching rates, respectively.

Results: Ivermectin treatment induced significantly higher An. arabiensis mortality on days 1 and 4, compared to untreated controls ( $p=0.02$ and $p<0.001$, respectively). However, this effect had declined by day 7 , with no significant difference in mortality between treated and control groups $(p=0.06)$. The mean survival time of mosquitoes fed on day 1 was 2.1 days, while those fed on day 4 survived 4.0 days. Mosquitoes fed on the treatment group at day 7 and 10 produced significantly lower numbers of eggs compared to the untreated controls $(p<0.001$ and $p=0.04$, respectively). An. arabiensis fed on day 7 on treated men also had lower larval hatching rates than mosquitoes fed on days 10 and 13 ( $p=0.003$ and $p=0.001$, respectively).

Conclusion: A single oral dose of ivermectin given to humans can induce mortality and reduce survivorship of An. arabiensis for 7 days after treatment. Ivermectin also had a delayed effect on fecundity of An. arabiensis that took bloodmeals from treated individuals on day 7 and 10. Additional studies are warranted using wild, insecticide-resistant mosquito populations, to confirm findings and a phase III evaluation among community members in Ethiopia is needed to determine the impact of ivermectin on malaria transmission.
\end{abstract}

Keywords: Anopheles arabiensis, Fecundity, Fertility, Ivermectin, Mortality

\section{Background}

Malaria is a disease transmitted by female Anopheles mosquitoes, caused by protozoan parasites of the genus Plasmodium. The disease predominately occurs in

\footnotetext{
*Correspondence: wondi89@gmail.com

${ }^{6}$ Department of Biology, Arba Minch University, Arba Minch, Ethiopia

Full list of author information is available at the end of the article
}

tropical and sub-tropical regions and remains a major public health problem. Most malaria cases in 2017 occurred in the World Health Organization (WHO) African Region (92\%), followed by the WHO South-East Asia Region (5\%) and the WHO Eastern Mediterranean Region (2\%). Of the 87 countries reporting indigenous malaria cases in 2017, 15 countries (all in sub-Saharan Africa) and India carried $80 \%$ of the global malaria 
burden. Malaria is estimated to have decreased by $20 \%$ in 20 countries, mainly due to the wide use of vector control interventions, and increased with a similar magnitude in another 20 countries between 2016 and 2017 [1].

Current malaria vector control programs mainly rely on the use of chemical insecticides from five classes [2]. However, the development of insecticide resistance [3, 4] and behavioural changes, including early and outdoor biting activities [5], may jeopardize the effectiveness of malaria vector control interventions. In Ethiopia, vector behavioural changes, such as behavioural avoidance, feeding on animals, resting outdoors away from indoor treated surfaces, and feeding upon humans when they are not protected, all contribute to sustaining residual malaria transmission [6]. The zoophagic tendency of Anopheles arabiensis [7] presents an opportunity to control this species by treating cattle with ivermectin and it is an important option to target zoophagic mosquitoes.

To achieve malaria elimination before 2030, as set by the WHO [8], innovation of vector control tools to counteract the emergence of drug and insecticide resistance is fundamental [9]. For this reason, ivermectin is receiving more attention as a potential tool to be used for malaria control [9-11]. This drug has been used since the 1980s for animal health to control parasitic diseases, including cattle onchocerciasis [12, 13], lymphatic filariasis $[14]$, and scabies and lice $[15,16]$. Evidence for the efficacy of ivermectin to reduce Anopheles survivorship and Plasmodium sporozoite rate is growing. Mass drug administration of ivermectin in southeastern Senegal for onchocerciasis and lymphatic filariasis dramatically affected the density of malaria vectors and reduced the proportion of Plasmodium falciparum infectious mosquitoes [17]. Furthermore, the survivorship of Anopheles gambiae sensu stricto (s.s.) that ingested blood of humans treated with $200 \mu \mathrm{g} / \mathrm{kg}$ ivermectin was reduced significantly after 1 day of treatment [18]; however, this effect was not apparent 14 days post-ingestion. This might be because ivermectin and/or its metabolites are removed from plasma over 12 days after treatment [19]. Even a single dose of ivermectin in small concentrations, can have a deleterious effect on mosquitoes before they become infectious and can reduce survival $[18,20]$; ivermectin-exposed mosquitoes are less likely to transmit Plasmodium parasites due to a shift in Anopheles populations to younger mosquitoes [10].

The implementation of ivermectin could contribute to insecticide resistance management. The occurrence of cross-resistance to ivermectin from currently used insecticides is less likely as its mechanism of action (inhibition of glutamate-gated chloride channels) is different [21]. However metabolic resistance could still affect the impact of ivermectin on mosquito mortality [22].
Treatment of cattle or humans with ivermectin, may represent a viable complementary vector control strategy. The aim of this study was to assess the effect of administering a single oral dose of ivermectin to humans on mortality, fecundity and fertility of a laboratory colony of $A n$. arabiensis in Ethiopia.

\section{Methods \\ Study area, design and participants}

This study was conducted from July 2017 to October 2017 at the Tropical and Infectious Diseases Research Centre, Jimma University in Sekoru, Oromia region $\left(7.922305^{\circ} \mathrm{N}\right.$, $\left.37.395320^{\circ} \mathrm{E}\right)$. The research centre is $246 \mathrm{~km}$ South-West of Addis Ababa, situated at an altitude of $1684 \mathrm{~m}$ above sea level. Six volunteer males aged $25-40$ years, weighing between 64 and $72 \mathrm{~kg}$ were recruited from Sekoru village, after receiving informed consent. The dosage of ivermectin given to volunteer range from 166.7 to $187.5 \mu \mathrm{g} / \mathrm{kg}$. The volunteers were assigned randomly to either treatment or control groups using a lottery method. Four of them received a recommended single oral dose of $12 \mathrm{mg}$ ivermectin for these weights and the other two individuals did not receive the drug (untreated controls). The entomology technicians (providing mosquitoes for feeding and performing mosquito dissections) were blinded to the treatment and control groups. The drug was obtained from the Ministry of Health, donated by the Mectizan donation program for onchocerciasis elimination in Ethiopia.

\section{Experimental procedure Mosquito rearing in the laboratory}

An insecticide-susceptible colony of $A n$. arabiensis (Debre Zeit: DZ) [23], reared under standard conditions of $27 \pm 2{ }^{\circ} \mathrm{C}, 70 \pm 10 \%$ relative humidity and $12 \mathrm{~h} / 12 \mathrm{~h}$ day/night cycles, was used for this experiment. Larvae were reared in plastic trays in distilled water and were provided a diet of ground Tetramin ${ }^{\circledR}$ fish food. Pupae were collected in cups and placed in $30 \times 30 \times 30 \mathrm{~cm}$ cages. Emerging adults were provided with $10 \%$ sugar solution for $3-5$ days.

\section{Mosquito feeding}

Prior to human feeding, female 3-5 day-old, An. arabiensis were starved of sugar solution for $4 \mathrm{~h}$. Twentyfour hours after ivermectin ingestion, human volunteers exposed their right arm to 90-100 starved female $A n$. arabiensis inside cages. A total of six cages (four for the ivermectin group, two for the untreated control) were used. Mosquitoes were allowed to feed for $30 \mathrm{~min}$. Unfed and fully un-engorged mosquitoes were removed from the cages using mouth aspirators. Then, fully fed 
mosquitoes were maintained on $10 \%$ sugar solution for 5 days. Mosquito mortality was recorded every $24 \mathrm{~h}$ for those 5 days. The feeding experiment was repeated at days $4,7,10$ and 13 post-ivermectin treatment using different batches of mosquitoes, following the same procedure (Fig. 1).

\section{Mortality estimation of Anopheles arabiensis}

Daily mortality of mosquitoes was monitored for 5 days after feeding for both treatment and control groups in each round. Dead mosquitoes were recorded and removed from the cages every day. New batches of $A n$. arabiensis were used in each replicate. Mosquitoes were considered dead if they were lying on the bottom of the cage and unable to move. If a mosquito was unable to fly yet it was able to stand on its legs, it was considered alive [24].

\section{Fecundity estimation of An. arabiensis}

Mosquito fecundity was measured starting day 7 post treatment because of the high mortality rate in the early days of follow-up. Mosquitoes were offered a blood meal from a volunteer on day 7,10 and 13 . To determine fecundity, 80 gravid mosquitoes from treatment groups and 40 from the control group were dissected on the fourth day after their blood meal using a dissecting microscope in round 3, 4 and 5. For dissection, female mosquitoes were anaesthetized using chloroform, placed on a clean microscope slide in a drop of distilled water. The thorax of a mosquito was gently grasped by a dissecting needle and the last two abdominal segments were gently pulled away using another dissecting needle to count the number of eggs (partially-formed eggs were also counted) in both ovaries.

\section{Fertility estimation of An. arabiensis}

In each round an additional 80 gravid An. arabiensis from the treatment group and 40 from the control group were gently transferred to individual $1.5 \mathrm{ml}$ Eppendorf tubes, containing a moist triangular piece of Whatman No. 1 filter paper with air holes in the cap and base, using a mouth aspirator. Laid eggs from the experimental and control groups were reared in separate plastic cups filled with distilled water. Hatched larvae were supplied with fish food $\left(\right.$ TetraMin $\left.^{\circledR}\right)$ daily in larval pans. The number of newly emerged larvae were recorded. Eggs that could not develop into larvae up to day 7 were considered infertile.

\section{Data analysis}

Data were recorded in appropriately designed forms, entered into Microsoft excel for data cleaning and exported to SPSS version 16 and R version 3.4.4 software for analysis. Analysis of variance were used to compare mean mortality, fecundity and fertility of mosquitoes

\begin{tabular}{|c|c|c|c|c|c|c|}
\hline \multirow{3}{*}{ Round 1} & \multicolumn{5}{|c|}{ 3-5 days old female mosquitoes selected } & \\
\hline & \multicolumn{4}{|c|}{ Treatment (4 Replications) } & \multicolumn{2}{|c|}{ Control ( 2 Replications) } \\
\hline & $\begin{array}{l}\text { Cage } 1 \text { (100 } \\
\text { Mosquitoes) }\end{array}$ & $\begin{array}{l}\text { Cage } 2 \text { (100 } \\
\text { Mosquitoes) }\end{array}$ & $\begin{array}{l}\text { Cage } 3 \text { (90 } \\
\text { Mosquitoes) }\end{array}$ & $\begin{array}{c}\text { Cage } 4 \text { (90 } \\
\text { Mosquitoes) }\end{array}$ & $\begin{array}{l}\text { Cage } 5 \text { (100 } \\
\text { Mosquitoes) }\end{array}$ & $\begin{array}{l}\text { Cage } 6 \text { (100 } \\
\text { Mosquitoes) }\end{array}$ \\
\hline Round 2 & $\begin{array}{l}\text { Cage } 1 \text { (100 } \\
\text { Mosquitoes) }\end{array}$ & $\begin{array}{l}\text { Cage } 2 \text { (100 } \\
\text { Mosquitoes) }\end{array}$ & $\begin{array}{l}\text { Cage } 3 \text { (100 } \\
\text { Mosquitoes) }\end{array}$ & $\begin{array}{l}\text { Cage } 4 \text { (100 } \\
\text { Mosquitoes) }\end{array}$ & $\begin{array}{l}\text { Cage } 5(100 \\
\text { Mosquitoes) }\end{array}$ & $\begin{array}{l}\text { Cage } 6(100 \\
\text { Mosquitoes })\end{array}$ \\
\hline Round 3 & $\begin{array}{l}\text { Cage } 1 \text { (100 } \\
\text { Mosquitoes) }\end{array}$ & $\begin{array}{l}\text { Cage } 2 \text { (100 } \\
\text { Mosquitoes) }\end{array}$ & $\begin{array}{l}\text { Cage } 3 \text { (100 } \\
\text { Mosquitoes) }\end{array}$ & $\begin{array}{l}\text { Cage } 4 \text { (100 } \\
\text { Mosquitoes) }\end{array}$ & $\begin{array}{l}\text { Cage } 5 \text { (100 } \\
\text { Mosquitoes) }\end{array}$ & $\begin{array}{l}\text { Cage } 6(100 \\
\text { Mosquitoes) }\end{array}$ \\
\hline Round 4 & $\begin{array}{l}\text { Cage } 1 \text { (100 } \\
\text { Mosquitoes) }\end{array}$ & $\begin{array}{l}\text { Cage } 2 \text { (100 } \\
\text { Mosquitoes) }\end{array}$ & $\begin{array}{l}\text { Cage } 3(100 \\
\text { Mosquitoes) }\end{array}$ & $\begin{array}{l}\text { Cage } 4(100 \\
\text { Mosquitoes) }\end{array}$ & $\begin{array}{l}\text { Cage } 5 \text { (100 } \\
\text { Mosquitoes) }\end{array}$ & $\begin{array}{l}\text { Cage } 6 \text { (100 } \\
\text { Mosquitoes) }\end{array}$ \\
\hline Round 5 & $\begin{array}{l}\text { Cage } 1 \text { (100 } \\
\text { Mosquitoes) }\end{array}$ & $\begin{array}{l}\text { Cage } 2 \text { (95 } \\
\text { Mosquitoes) }\end{array}$ & $\begin{array}{l}\text { Cage } 3(90 \\
\text { Mosquitoes) }\end{array}$ & $\begin{array}{l}\text { Cage } 4(100 \\
\text { Mosquitoes) }\end{array}$ & $\begin{array}{l}\text { Cage } 5 \text { (100 } \\
\text { Mosquitoes) }\end{array}$ & $\begin{array}{l}\text { Cage } 6 \text { (100 } \\
\text { Mosquitoes) }\end{array}$ \\
\hline
\end{tabular}

Fig. 1 Flow chart of the mosquito feeding procedures 
between treatment and control groups as well as among individual experimental group replicates. Descriptive statistics were used to calculate feeding rates of mosquitoes and hatching rates of eggs. Survivorship of mosquitoes was analysed using Kaplan-Meier survival curves. Mortality of mosquitoes was standardized and pooled prior to data analysis.

\section{Results}

\section{Effect of ivermectin on Anopheles arabiensis mortality}

The number of $A n$. arabiensis exposed to feed on humans were 2965 and out of this 2465 mosquitoes became fully engorged. The feeding rate of mosquitoes was $83.1 \%$ and an average of 493 mosquitoes were used per replicate. There were no significant differences in mosquito feeding rates between treatment and control groups $(82.5 \%$ and $84.5 \%$ average feeding rates, respectively $p=0.355)$. Overall feeding rates of mosquitoes at different feeding days are shown in Table 1 . The mean mortality rate during the 5-day follow-up was high on day 1, 4 and 7 post-treatment compared to the controls. The mean daily mortality of mosquitoes fed on days 10 and 13 was similar to the control mortality (Table 2 and Fig. 2).

The mean number of dead $A n$. arabiensis, after feeding on ivermectin-treated individuals on day 1 post administration, was 13.8; this was significantly higher than mortality after feeding on control individuals (3.7 dead; $p=0.02$ ), during 5 days of follow-up (Table 2). Similarly, the mean mortality of $A n$. arabiensis fed on treated volunteers 4 days post ivermectin treatment was also significantly different from controls $(p<0.001)$. There was no difference in mosquito mortality between treatment and control groups from day 7 post ivermectin administration onwards (Table 2).

The effect of ivermectin on mean 5-day mortality of An. arabiensis between different feeding intervals varied among treatment groups and controls, according to a one-way ANOVA and a post hoc multiple comparisons test (Fig. 3). Mean daily mortality of An. arabiensis fed on ivermectin treated volunteers on day 1 and day 4 were not significantly different $(p=0.73)$ (Fig. 3). By comparison, mean daily mortality of $A n$. arabiensis fed on day 1 was significantly higher than those feed

Table 1 Feeding rates of mosquitoes at different feeding times

\begin{tabular}{|c|c|c|c|c|c|c|}
\hline \multirow[t]{2}{*}{ Feeding day } & \multicolumn{4}{|l|}{ Treatment } & \multicolumn{2}{|l|}{ Control } \\
\hline & Replicate 1 & Replicate 2 & Replicate 3 & Replicate 4 & Replicate 1 & Replicate 2 \\
\hline 1DAT & 74.00 & 80.00 & 81.11 & 86.67 & 83.00 & 77.00 \\
\hline 4DAT & 80.00 & 91.00 & 73.00 & 81.00 & 86.00 & 82.00 \\
\hline 7DAT & 87.00 & 86.00 & 79.00 & 82.00 & 94.00 & 83.00 \\
\hline 10DAT & 90.00 & 86.00 & 79.00 & 77.00 & 86.00 & 85.00 \\
\hline 13DAT & 87.00 & 83.16 & 94.44 & 72.00 & 92.00 & 78.00 \\
\hline
\end{tabular}

DAT days after treatment

Table 2 Mean daily mortality of An. arabiensis fed on treated or control volunteers at different feeding days after ivermectin administration and follow-up for five consecutive days

\begin{tabular}{|c|c|c|c|c|c|c|}
\hline \multirow[t]{2}{*}{ Feeding day } & \multirow[t]{2}{*}{ Exposure } & \multirow[t]{2}{*}{ Mosquito, N } & \multirow{2}{*}{$\begin{array}{l}\text { Mean daily } \\
\text { mortality }\end{array}$} & \multicolumn{2}{|c|}{$95 \% \mathrm{Cl}$ for mean } & \multirow[t]{2}{*}{$P$ value } \\
\hline & & & & Lower bound & Upper bound & \\
\hline \multirow[t]{2}{*}{ 1DAT } & Treatment & 76 & 13.83 & 7.84 & 19.81 & 0.02 \\
\hline & Control & 80 & 3.70 & 1.82 & 5.59 & \\
\hline \multirow[t]{2}{*}{ 4DAT } & Treatment & 81 & 11.19 & 8.52 & 13.87 & 0.00 \\
\hline & Control & 84 & 3.46 & 1.35 & 5.57 & \\
\hline \multirow[t]{2}{*}{ 7DAT } & Treatment & 84 & 4.74 & 3.57 & 5.91 & 0.06 \\
\hline & Control & 89 & 2.85 & 0.99 & 4.70 & \\
\hline \multirow[t]{2}{*}{ 10DAT } & Treatment & 83 & 2.76 & 2.26 & 3.25 & 0.38 \\
\hline & Control & 86 & 2.33 & 1.23 & 3.43 & \\
\hline \multirow[t]{2}{*}{ 13DAT } & Treatment & 81 & 2.52 & 1.45 & 3.59 & 0.80 \\
\hline & Control & 85 & 2.73 & 1.33 & 4.14 & \\
\hline
\end{tabular}

Feeding day: the day when An. arabiensis mosquitoes took a bloodmeal from ivermectin treated or control volunteers after drug administration

$\mathrm{Cl}$ confidence interval, DAT days after treatment, $\mathrm{N}$ number of An. arabiensis 


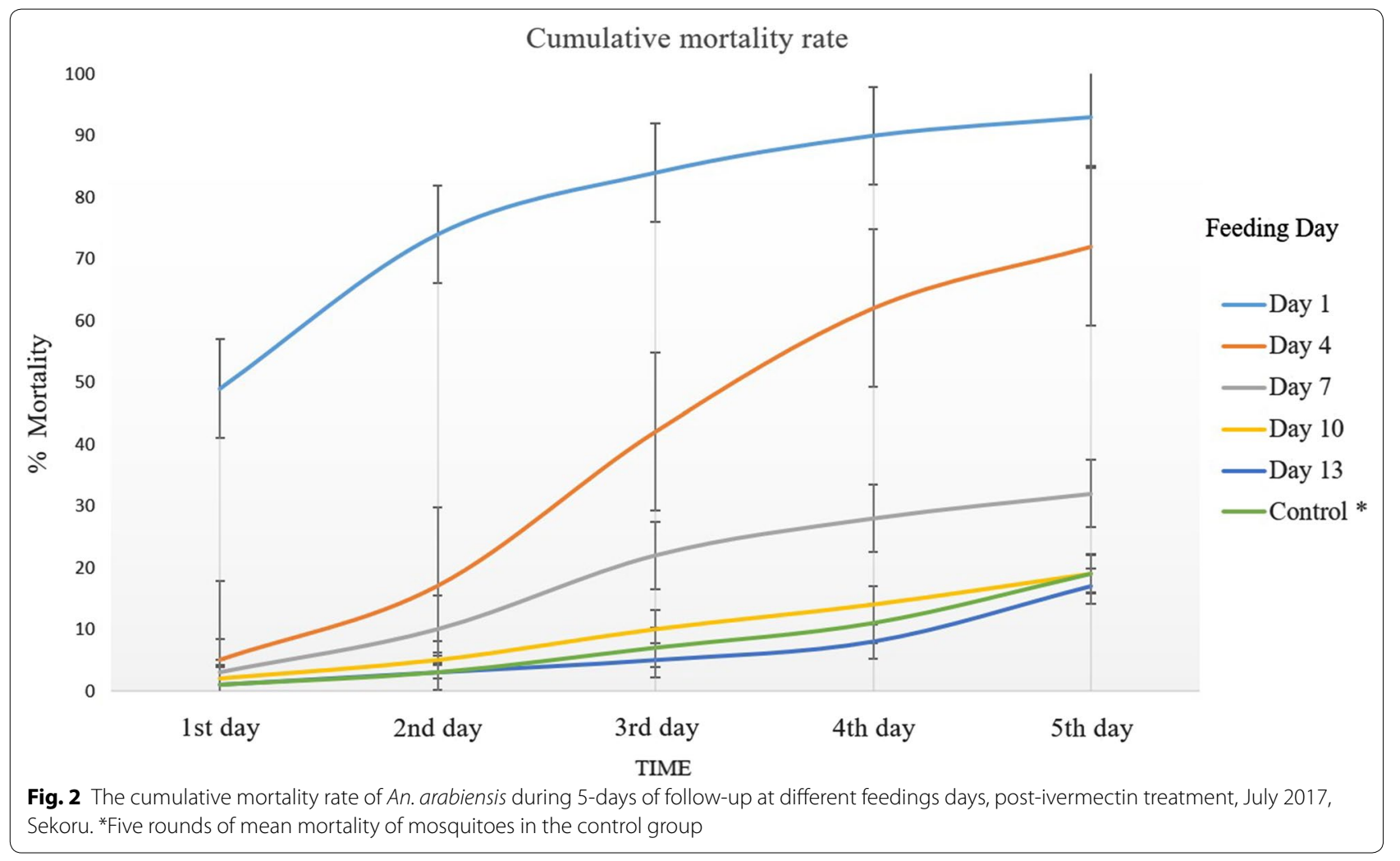

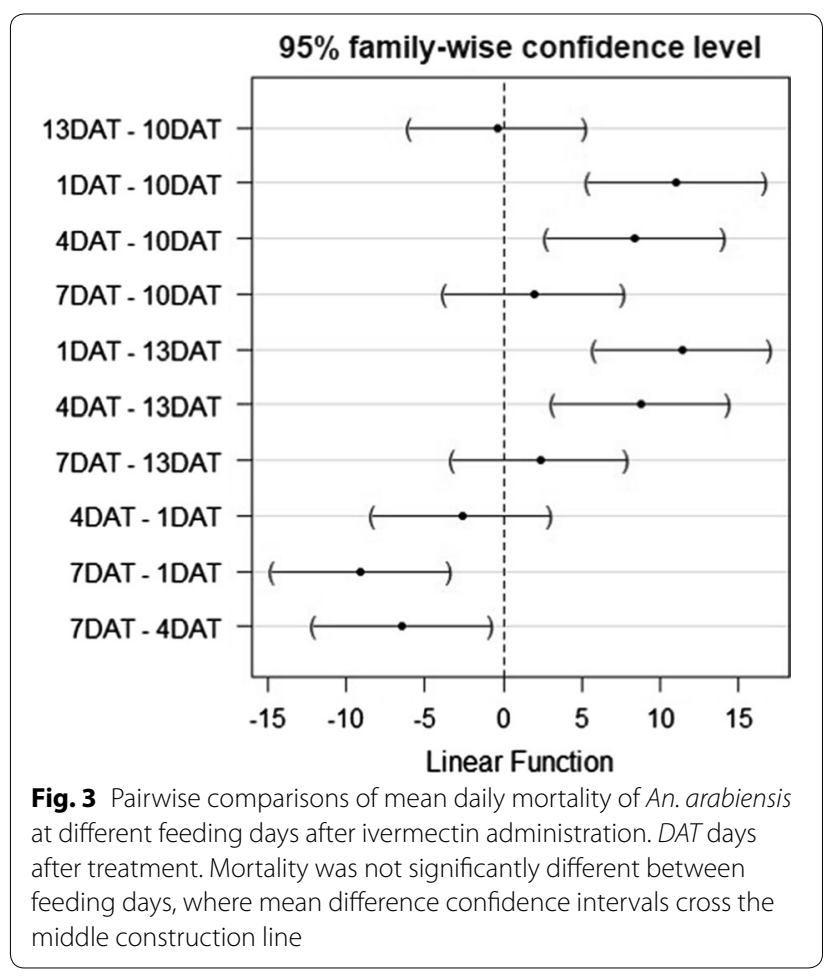

on days 7, 10 and $13(p<0.001)$. In addition, mean daily mortality of An. arabiensis fed on day 4 post treatment, was significantly different from day 7 ( $p=0.011,95 \%$ CI
$0.9824-11.92)$, day $10(p<0.001,95 \%$ CI $2.96-13.90)$ and day $13(p<0.001,95 \%$ CI 3.20-14.15). However, mean daily mortality rates of An. arabiensis fed on ivermectintreated volunteers on days 7, 10 and 13 were not statistically different ( $p=0.900,95 \%$ CI 3.49-7.45).

\section{Effect of ivermectin on An. arabiensis fecundity}

The effect of ivermectin on An. arabiensis fecundity on days 1 and 4 after treatment was not assessed due to high mortality of $A n$. arabiensis during this period. The mean number of eggs laid by An. arabiensis, which fed on treated volunteers on day 7 , was $42.24 \pm 6.60$, compared to $110.05 \pm 4.81$ in the control group $(p<0.001)$. The mean number of eggs laid by An. arabiensis, which took blood meals from treated volunteers on day 10 post ivermectin administration was also significantly different compared to the control group $(p=0.04)$. However, ivermectin did not have a significant effect on fecundity of An. arabiensis after day 13 post drug administration $(p=0.34)$ (Table 3).

The effect of ivermectin on fecundity of An. arabiensis were compared between days 7, 10 and 13 after treatment. The mean number of eggs laid by An. arabiensis, which fed on treated volunteers on day 7 was significantly different compared to day 10 (mean difference: 52.7; 95\% CI 41.9-63.9; $p<0.001$ ) and day 13 (mean difference: 
Table 3 Mean number of eggs per mosquito fed on ivermectin treated and non-treated volunteers at different feeding times

\begin{tabular}{|c|c|c|c|c|c|c|}
\hline \multirow[t]{2}{*}{ Feeding day } & \multirow[t]{2}{*}{ Exposure } & \multirow[t]{2}{*}{ Mosquito $\mathrm{N}$} & \multirow{2}{*}{$\begin{array}{l}\text { Mean no. eggs/ } \\
\text { ovary }\end{array}$} & \multicolumn{2}{|c|}{$95 \% \mathrm{Cl}$ for mean } & \multirow[t]{2}{*}{ P-value } \\
\hline & & & & Lower bound & Upper bound & \\
\hline \multirow[t]{2}{*}{ 7DAT } & Treatment & 80 & 42.24 & 31.74 & 52.73 & $<0.001$ \\
\hline & Control & 40 & 110.05 & 66.85 & 153.25 & \\
\hline \multirow[t]{2}{*}{ 10DAT } & Treatment & 80 & 94.99 & 84.98 & 105 & 0.04 \\
\hline & Control & 40 & 112.35 & 46.91 & 177.79 & \\
\hline \multirow[t]{2}{*}{ 13DAT } & Treatment & 80 & 114.6 & 110.31 & 118.89 & 0.34 \\
\hline & Control & 40 & 110.85 & 52.4 & 169.3 & \\
\hline
\end{tabular}

Feeding day: the day when An. arabiensis mosquitoes took a bloodmeal from ivermectin treated or control volunteers after drug administration

$S D$ standard deviation, SE standard error, $\mathrm{Cl}$ confidence interval, $\mathrm{N}$ number of gravid An. arabiensis

72.3; CI 61.2-83.5; $p<0.001)$. There was also a significant difference in mosquito fecundity between days 10 and 13 (mean difference: 19.6; 95\% CI 8.5-30.7; $p<0.001$ ).

\section{Effect of ivermectin on An. arabiensis fertility}

The effect of ivermectin on An. arabiensis fertility on days 1 and 4 post ivermectin treatment was also not assessed. Mean hatching rates of eggs, laid from mosquitoes fed on treated volunteers compared to the control group, were $73.8 \%$ vs. $91.3 \%$ on day $7,88.6 \%$ vs. $91.9 \%$ on day 10 and $90.5 \%$ vs. $92.5 \%$ on day 13 . Significant differences in hatching rates between $A n$. arabiensis, fed on treated vs control individuals, were observed on day 7 $(p=0.03)$ but not days 10 and $13(p=0.07$ and $p=0.34$, respectively).

Mean hatching rate of eggs from An. arabiensis, which took a blood meal on day 7 after ivermectin administration, was significantly lower compared to day 10 (mean difference: 14\%; 95\% CI 6.8-23.45; $p=0.03$ ) and day 13 (mean difference: $16 \%$; 95\% CI $8-25.3 ; p<0.001$ ). However, the effect of ivermectin on fertility was not significant between days 10 and 13 post treatment (mean difference: 1.9\%; 95\% CI 6.8-10.6; $p=0.82$ ) (Table 4).
Effect of ivermectin on An. arabiensis survival

The effect of ivermectin on $A n$. arabiensis survival was assessed for five consecutive days post feeding on treated or control participants. All live mosquitoes on day 5 were considered as censored.

The mean survival time of $A n$. arabiensis, which blood fed from ivermectin treated volunteers on day 1 post treatment was 2.1, compared to 5.5 in the control group $(p<0.001)$ (Table 5). Statistically significant differences in mean survival time of exposed An. arabiensis, compared to control mosquitoes, were also observed on day 4 (mean survival days: $4.02,95 \%$ CI $3.69-4.36$; $p<0.001$ ) and day 7 (mean survival days: 5.06; 95\% CI 4.73-5.39; $p=0.01$ ), post treatment. Otherwise no statistically significant difference was demonstrated for days 10 and 13 (Table 5).

As shown in Fig. 4, the majority of $A n$. arabiensis that fed on treated volunteers on day 1 post ivermectin administration died within 2 days. By comparison, most An. arabiensis, which took a blood meal from treated volunteers on day 4 post-treatment, died within 4 days.

Table 4 Mean hatching rate of eggs from An. arabiensis mosquitoes fed on ivermectin treated and non-treated volunteers at different feeding days

\begin{tabular}{|c|c|c|c|c|c|c|}
\hline \multirow[t]{2}{*}{ Feeding day } & \multirow[t]{2}{*}{ Exposure } & \multirow{2}{*}{$\begin{array}{l}\text { Mean no. of eggs } \\
\text { laid }\end{array}$} & \multirow[t]{2}{*}{$\%$ mean hatching } & \multicolumn{2}{|c|}{$95 \% \mathrm{Cl}$ for mean } & \multirow[t]{2}{*}{ P-value } \\
\hline & & & & Lower bound & Upper bound & \\
\hline \multirow[t]{2}{*}{ 7DAT } & Treatment & 44 & 73.85 & 62.37 & 85.33 & 0.03 \\
\hline & Control & 110 & 91.29 & 78.73 & 103.85 & \\
\hline \multirow[t]{2}{*}{ 10DAT } & Treatment & 97 & 88.62 & 86.15 & 91.09 & 0.07 \\
\hline & Control & 119 & 91.9 & 77.63 & 106.17 & \\
\hline \multirow[t]{2}{*}{ 13DAT } & Treatment & 116 & 90.53 & 87.5 & 93.56 & 0.34 \\
\hline & Control & 122 & 92.51 & 90.82 & 94.2 & \\
\hline
\end{tabular}


Table 5 Mean survival time of mosquitoes during 5-days of follow-up at different feeding days

\begin{tabular}{|c|c|c|c|c|c|c|}
\hline \multirow[t]{2}{*}{ Feeding day } & \multirow[t]{2}{*}{ Exposure } & \multirow{2}{*}{$\begin{array}{l}\text { Mean survival time } \\
\text { (days) }\end{array}$} & \multicolumn{2}{|l|}{$95 \% \mathrm{Cl}$} & \multirow[t]{2}{*}{$\mathrm{X}^{2}$} & \multirow[t]{2}{*}{ P-value } \\
\hline & & & Lower bound & Upper bound & & \\
\hline \multirow[t]{2}{*}{ 1DAT } & Treatment & 2.13 & 1.80 & 2.46 & 117.1 & $<0.001$ \\
\hline & Control & 5.53 & 5.30 & 5.75 & & \\
\hline \multirow[t]{2}{*}{ 4DAT } & Treatment & 4.02 & 3.69 & 4.36 & 49.9 & $<0.001$ \\
\hline & Control & 5.60 & 5.39 & 5.80 & & \\
\hline \multirow[t]{2}{*}{ 7DAT } & Treatment & 5.06 & 4.73 & 5.39 & 6.1 & 0.01 \\
\hline & Control & 5.66 & 5.47 & 5.85 & & \\
\hline \multirow[t]{2}{*}{ 10DAT } & Treatment & 5.47 & 5.20 & 5.74 & 0.0 & 0.87 \\
\hline & Control & 5.56 & 5.34 & 5.77 & & \\
\hline \multirow[t]{2}{*}{ 13DAT } & Treatment & 5.63 & 5.41 & 5.84 & 0.02 & 0.89 \\
\hline & Control & 5.65 & 5.45 & 5.85 & & \\
\hline
\end{tabular}

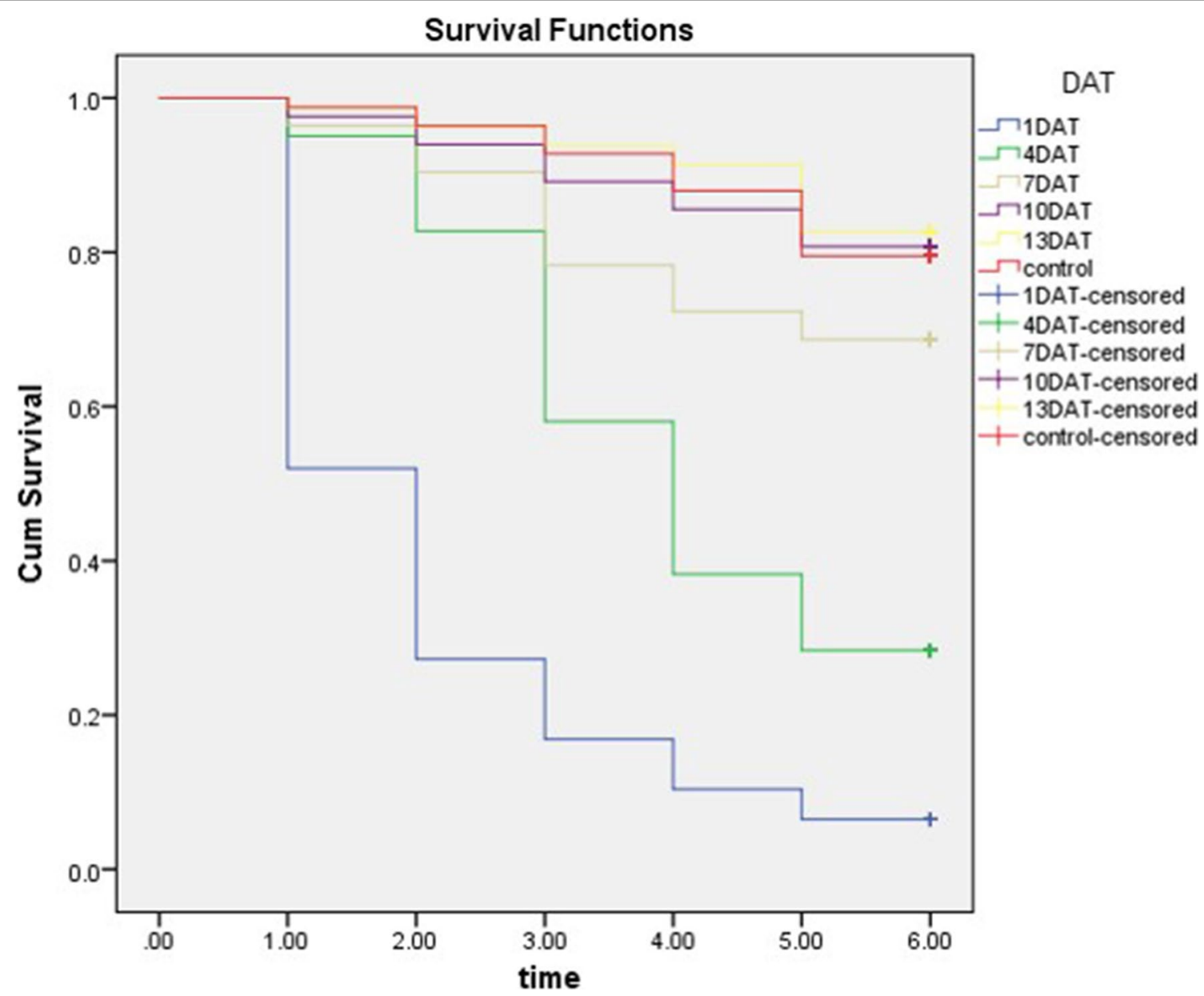

Fig. 4 Kaplan-Meier survival curve of An. arabiensis during 5 days of follow-up after different feeding days post ivermectin treatment

\section{Discussion}

In this study, a single oral dose of ivermectin induced $A n$. arabiensis mortality and reduced fecundity and fertility after feeding on treated men, compared to controls.
Previous studies conducted on the effects of ivermectin on different disease vectors documented that ivermectin reduced the survivorship of Anopheles stephensi, Aedes aegypti, Culex pipiens and Culex quinquefasciatus [25]. 
The majority of tested mosquitoes, which fed 1 day post treatment died within 2 days and 93\% mortality was recorded on day 5 post-ingestion. In agreement with the present study, results from Kenya showed that nearly half of blood fed An. gambiae from the ivermectin group died on the second day and $90 \%$ died on day 6 , compared to $9 \%$ mortality in the control group on day 6 [26]. In addition, a dose of $300 \mu \mathrm{g} / \mathrm{kg}$ ivermectin per day given for 3 days to malaria patients can reduce mosquito survival for at least 28 days after treatment [27]. Multiple studies support the observation that mass drug administration of ivermectin reduces the survivorship of mosquitoes $[28,29]$. In West Africa, following ivermectin mass drug administration (MDA), survival of An. gambiae declined by more than $33 \%$ for 6 days, with reductions of sporozoites by $77 \%$ in the following 2 weeks; and a reduction in parity rate was also observed [30]. Ivermectin-containing blood meals have also been shown to reduce the survivorship of principal malaria vectors in different parts of the world [18, 20, 28, 29, 31-33].

The present study revealed that mosquito survival was significantly reduced after the ingestion of ivermectin from treated humans on 1 and 4 days after treatment. Mortality of mosquitoes started to decrease from day 7 . Therefore, day 7 could be the re-dosing time of ivermectin in this context. This is one pharmacological strategy recommended by the WHO to increase the efficacy of ivermectin [9]. However, this is hard to do logistically in the community unless a longer lasting formulation of ivermectin is developed in the future. The death rate of mosquitoes on day 10 and 13 day after treatment were similar to the control group, which may be attributed to the pharmacokinetics of ivermectin in the human body. Since the concentration of ivermectin and/or its metabolites are excreted in faeces every day, the residual concentration found in the plasma is also reduced day to day $[16$, 34].

The current study revealed that the number of eggs observed in the mosquitoes' ovaries was reduced after the ingestion of ivermectin on 7 and 10 days after treatment. Studies conducted on Anopheles aquasalis documented a similar effect of ivermectin on mosquito fecundity [35]. In addition to this, a study by Gardner et al. [31] showed a reduction in fecundity of Anopheles quadrimaculatus, exposed to $24 \mu \mathrm{g} / \mathrm{kg}$ ivermectin. These and the current study findings indicate that ivermectin can reduce mosquito density, prior to completion of the gonotrophic cycle [36].

Ivermectin also impacted mosquito fertility at day 7 post-treatment, in agreement with previous studies done on cattle, which also showed reduced fertility [29]. The effect of ivermectin on fertility of Ae. aegypti, Aedes albopictus, and $C x$. quinquefasciatus has been reported
[37]. Furthermore, Gardner et al. [31] also showed the effect of $24 \mu \mathrm{g} / \mathrm{kg}$ ivermectin on hatching rate of $A n$. quadrimaculatus mosquitoes. All of these physiological effects contribute to the reduction of vector population density.

This study has several strengths and limitations. The study was conducted using susceptible colony mosquitoes and, therefore, these findings cannot yet be directly extrapolated to wild mosquito populations. Additional studies, in areas characterized by different insecticide resistance intensities and underlying mechanisms are warranted to validate these phenomena. However, the study showed the delayed effect of a single oral dose of ivermectin used to treat onchocerciasis on the mortality, fertility and fecundity of mosquitoes, which is considered as the strength of the study.

\section{Conclusions}

A single oral dose of ivermectin provided to humans can induce mortality and reduce survivorship of $A n$. arabiensis for 7 days after treatment. It also had a delayed effect on fecundity of An. arabiensis that took blood meal from treated individuals on day 7 and 10 after ivermectin administration. Moreover, a delayed effect on fertility was observed when An. arabiensis took blood meal from treated volunteers on 7 days after treatment. Together these effects demonstrated the potential for ivermectin to reduce An. arabiensis population densities.

\section{Recommendations}

The effect of ivermectin on wild population survival, fecundity, and fertility must be studied before public health use. In addition, future studies are needed to investigate the delayed effects of ivermectin on survival, fecundity, and fertility of insecticide resistant mosquito populations in Ethiopia and in other malaria endemic countries.

\section{Abbreviations \\ DAT: days after treatment; EPHI: Ethiopian Public Health Institute; IRS: indoor residual spraying; LLINs: long-lasting insecticidal nets; MDA: Mass Drug Admin- istration; PMI: President's Malaria Initiative; $\mathrm{RH}$ : relative humidity; WHO: World Health Organization.}

\section{Acknowledgements}

We would like to thank NORHED-AMU for their support to carry out this research. And also we would like to thank the volunteers who took part in the study, entomology technicians Mr. Abdo Jemal, Mr. Huseen Yimama and Mrs Zara Abdura working at Sekoru insect village for their assistance and Dr. Yosef Tekle-Giorgis from Hawassa University for his help in data analysis.

\section{Authors' contributions}

WM: Participated in study design, laboratory work, data analysis and prepared draft manuscript. MB: participated in study design, manuscript write-up. LAM: participated in manuscript write-up. DY: participated laboratory work 
and manuscript write-up. AW: participated in study design and manuscript write-up. FM: participated in study design, laboratory work, data analysis and manuscript write-up. All authors read and approved the final manuscript.

\section{Funding}

Not applicable.

\section{Availability of data and materials}

Not applicable.

\section{Ethics approval and consent to participate}

Oral and written informed consent was obtained from volunteers participating during the study. The six study volunteers were informed about side effects of ivermectin and malaria transmission by vectors. Scientific and Ethical approval were obtained from the Scientific and Ethical Review Office (SERO) of EPHI on 04/01/2017.

\section{Consent of publication}

Not applicable.

\section{Competing interests}

The authors declare that they have no competing interests.

\section{Author details}

${ }^{1}$ Ethiopian Public Health Institute, Addis Ababa, Ethiopia. ${ }^{2}$ Abt Associates, PMI Vectorlink Project in Ethiopia, Addis Ababa, Ethiopia. ${ }^{3}$ Department of Disease Control, London School of Hygiene and Tropical Medicine, London, UK. ${ }^{4}$ Tropical and Infectious Disease Research Center, Jimma University, Jimma, Ethiopia. ${ }^{5}$ Department of Medical Laboratory Sciences and Pathology, College of Health Sciences, Jimma University, Jimma, Ethiopia. ${ }^{6}$ Department of Biology, Arba Minch University, Arba Minch, Ethiopia.

Received: 23 July 2019 Accepted: 24 October 2019

Published online: 08 November 2019

\section{References}

1. WHO. Recommended insecticides for indoor residual spraying against malaria vectors. Geneva: World Health Organization; 2018. https://www who.int/neglected_diseases/vector_ecology/vector-control/Insecticid es_IRS_22_September_2018.pdf?ua=1. Accessed 17 Jun 2019.

2. WHO. World malaria report. Geneva: World Health Organization; 2018.

3. Christian R, Koekemoer L, Fettene M, Olana D, Coetzee M. Insecticide resistance in Anopheles arabiensis from Ethiopia. African Entomol. 2013;21:89-94.

4. FY 2017 Ethiopian Malaria Operation Plan. 2017. https://www.pmi.gov/ resource-library/mops/fy-2017. Accessed 20 Apr 2019.

5. Kenea O, Balkew M, Tekie H, Gebre-Michael T, Deressa W, Loha E, et al. Human-biting activities of Anopheles species in south-central Ethiopia. Parasit Vectors. 2016;9:527.

6. WHO. Control of residual malaria parasit transmission. Geneva: World Health Organization; 2014.

7. Massebo F, Balkew M, Gebre-Michael T, Lindtjørn B. Zoophagic behaviour of anopheline mosquitoes in southwest Ethiopia: opportunity for malaria vector control. Parasit Vectors. 2015;8:645.

8. WHO. Global technical strategy for malaria 2016-2030. Geneva: World Health Organization; 2015.

9. WHO. Ivermectin for malaria transmission control: technical consultation meeting. Geneva: World Health Organization; 2016.

10. Chaccour CJ, Kobylinski KC, Bassat Q, Bousema T, Drakeley C, Alonso P, et al. Ivermectin to reduce malaria transmission: a research agenda for a promising new tool for elimination. Malar J. 2013;12:153.

11. Chaccour CJ, Rabinovich NR, Slater H, Canavati SE, Bousema T, Lacerda $M$, et al. Establishment of the Ivermectin Research for Malaria Elimination Network: updating the research agenda. Malar J. 2015;14:243.

12. Campbell WC. Ivermectin: a reflection on simplicity (Nobel lecture). Angew Chem Int Ed Engl. 2016;55:10184-9.

13. Thylefors B. The Mectizan donation program (MDP). Ann Trop Med Parasitol. 2008;102:39-44.
14. Ottesen EA, Hooper PJ, Bradley M, Biswas G. The global programme to eliminate lymphatic filariasis: health impact after 8 years. PLoS Negl Trop Dis. 2008;2:e317.

15. Chosidow O, Giraudeau B, Cottrell J, Izri A, Hofmann R, Mann SG, et al. Oral ivermectin versus malathion lotion for difficult-to-treat head lice. N Engl J Med. 2010;362:896-905.

16. Richard-Lenoble D, Chandenier J, Gaxotte P. Ivermectin and filariasis. Fundam Clin Pharmacol. 2003;17:199-203.

17. Kobylinski KC, Sylla M, Chapman PL, Sarr MD, Foy BD. Ivermectin mass drug administration to humans disrupts malaria parasite transmission in Senegalese villages. Am J Trop Med Hyg. 2011;85:3-5.

18. Chaccour C, Lines J, Whitty CJ. Effect of ivermectin on Anopheles gambiae mosquitoes fed on humans: the potential of oral insecticides in malaria control. J Infect Dis. 2010;202:113-6.

19. WHO. Notes on the design of bioequivalence study: Ivermectin. Geneva: World Health Organization; 2015. https://www.who.int/negle cted_diseases/vector_ecology/vectorcontrol/Insecticides_IRS_22_ September_2018.pdf?ua=1.

20. Kobylinski KC, Deus KM, Butters MP, Hongyu T, Gray M, da Silva IM, et al. The effect of oral anthelmintics on the survivorship and re-feeding frequency of anthropophilic mosquito disease vectors. Acta Trop. 2010;116:119-26.

21. Cully D. Cloning of an avermectin-sensitive glutamate-gated chloride channel from Caenorhabditis elegans. Nature. 1994;371:707-11.

22. Chaccour CJ, Hammann F, Alustiza M, Castejon S, Tarimo BB, Abizanda G, et al. Cytochrome P450/ABC transporter inhibition simultaneously enhances ivermectin pharmacokinetics in the mammal host and pharmacodynamics in Anopheles gambiae. Sci Rep. 2017;7:8535.

23. Balkew M, Ibrahim M, Koekemoer LL, Brooke BD, Engers H, Aseffa A, et al. Insecticide resistance in Anopheles arabiensis (Diptera: Culicidae) from villages in central, northern and south west Ethiopia and detection of kdr mutation. Parasit Vectors. 2010;3:40.

24. WHO. Test procedures for insecticide resistance monitoring in malaria vector mosquitoes. Geneva: World Health Organization; 2016.

25. Pampiglione S, Majori G, Petrangeli G, Romi R. Avermectins, MK-933 and MK-936, for mosquito control. Trans R Soc Trop Med Hyg. 1985;79:797-9.

26. Derua YA, Kisinza WN, Simonsen PE. Differential effect of human ivermectin treatment on blood feeding Anopheles gambiae and Culex quinquefasciatus. Parasit Vectors. 2015;8:130.

27. Smit MR, Ochomo EO, Aljayyoussi G, Kwambai TK, Abong'o BO, Chen T, et al. Safety and mosquitocidal efficacy of high-dose ivermectin when co-administered with dihydroartemisinin-piperaquine in Kenyan adults with uncomplicated malaria (IVERMAL): a randomised, double-blind, placebo-controlled trial. Lancet Infect Dis. 2018;18:615-26.

28. Foley D, Bryan J, Lawrence G. The potential of ivermectin to control the malaria vector Anopheles farauti. Trans R Soc Trop Med Hyg. 2000;94:625-8.

29. Fritz M, Siegert P, Walker E, Bayoh M, Vulule J, Miller J. Toxicity of bloodmeals from ivermectin-treated cattle to Anopheles gambiae s.I. Ann Trop Med Parasitol. 2009;103:539-47.

30. Alout H, Krajacich BJ, Meyers Jl, Grubaugh ND, Brackney DE, Kobylinski $\mathrm{KC}$, et al. Evaluation of ivermectin mass drug administration for malaria transmission control across different West African environments. Malar J. 2014;13:417.

31. Gardner K, Meisch M, Meek C, Biven W. Effects of ivermectin in canine blood on Anopheles quadrimaculatus, Aedes albopictus and Culex salinarius. J Am Mosq Control Assoc. 1993;9:400-2.

32. Jones J, Meisch M, Meek C, Bivin W. Lethal effects of ivermectin on Anopheles quadrimaculatus. J Am Mosq Control Assoc. 1992;8:278-80.

33. Bockarie M, Hii J, Alexander N, Bockarie F, Dagoro H, Kazura J, et al. Mass treatment with ivermectin for filariasis control in Papua New Guinea: impact on mosquito survival. Med Vet Entomol. 1999;13:120-3.

34. Smit MR, Ochomo EO, Waterhouse D, Kwambai TK, Abong'o BO, Bousema T, et al. Pharmacokinetics-pharmacodynamics of high-dose ivermectin with dihydroartemisinin-piperaquine on mosquitocidal activity and QT-prolongation (IVERMAL). Clin Pharmacol Ther. 2019;105:388-401. 
35. Sampaio VS, Beltrán TP, Kobylinski KC, Melo GC, Lima JB, Silva SG, et al. Filling gaps on ivermectin knowledge: effects on the survival and reproduction of Anopheles aquasalis, a Latin American malaria vector. Malar J. 2016;15:491.

36. Chaccour C, Rabinovich NR. Ivermectin to reduce malaria transmission II. Considerations regarding clinical development pathway. Malar J. 2017;16:166.
37. Tesh RB, Guzman H. Mortality and infertility in adult mosquitoes after the ingestion of blood containing ivermectin. Am J Trop Med Hyg. 1990;43:229-33.

\section{Publisher's Note}

Springer Nature remains neutral with regard to jurisdictional claims in published maps and institutional affiliations.
Ready to submit your research? Choose BMC and benefit from:

- fast, convenient online submission

- thorough peer review by experienced researchers in your field

- rapid publication on acceptance

- support for research data, including large and complex data types

- gold Open Access which fosters wider collaboration and increased citations

- maximum visibility for your research: over $100 \mathrm{M}$ website views per year

At BMC, research is always in progress.

Learn more biomedcentral.com/submissions 